\title{
Effects of natural weathering on the performance of high solar reflective index paint surfaces exposed in harsh climatic condi- tions of United Arab Emirates
}

\author{
Tirumala Uday Kumar Nutakki ${ }^{1, *}$ and Waqar Ullah Kazim ${ }^{2}$ \\ 1 School of Engineering, American University of Ras Al Khaimah (AURAK), Po Box: 10021, Ras Al Khaimah, \\ United Arab Emirates; uday.kumar@aurak.ac.ae \\ 2 RAK Research and Innovation Center, American University of Ras Al Khaimah (AURAK), Po Box: 10021, \\ Ras Al Khaimah, United Arab Emirates; Waqar.ullah@aurak.ac.ae \\ * Correspondence: uday.kumar@aurak.ac.ae;
}

\begin{abstract}
Solar reflective index (SRI) is one of the important parameters in the analysis of a building's energetic and thermal performance, especially for "cool" reflective paints or coatings. However, there exists less information on the typical performance of the cool materials exposed for long term in the Middle East and more specifically in the United Arab Emirates (UAE). In this study, we determined values of reflectance, emittance, solar reflective index (SRI), and color difference, for three different high SRI white paints exposed naturally on low and high sloped racks for three years. After 3 years, reflectance values of exposed paint panels significantly decreased with an increased color difference in comparison with original unexposed paint surfaces. Emissivity of the paint changed very little for all of the exposed samples, but SRI, determined from both the reflectance and emittance, was reduced from between 95 and 110 to between 60 and 90 after three years. This appeared to be related to exposure to high temperatures, UV radiation, and adhesion of airborne contaminants in conjunction with low precipitation. Macroscopically, panels exposed on a low slope were the most discolored with the greatest presence of dust infusion and reduction in increase in surface temperatures which was demonstrated through thermal imaging. Such natural weathering research study is necessary for the development of standard exposure tests and determination of various control elements to increase the durability of cool materials in hot and arid climatic conditions of UAE.
\end{abstract}

Keywords: Cool materials, cool coatings, solar reflective index, solar reflectance, thermal emittance, natural weathering, green buildings, reflective paints

\section{Introduction}

In the current urban world, most of the horizontal surface area of cities is comprised of building roofs and paved surfaces. Typically, these consist of dark and dry surfaces such as tar-covered roofs and black asphalt parking lots, and these surfaces absorb solar heat [1]. On a sunny day, they can be as much as $50^{\circ} \mathrm{C}$ hotter than the air and then remain warm into the night, creating a phenomenon called an "urban heat island [2]." Night-time temperatures in paved urban and suburban areas can be more than $20^{\circ} \mathrm{C}$ higher than nonurban and vegetated areas. Especially, in a climate such as the United Arab Emirates (UAE), where air-conditionings are used year-round, this is undesirable [3]. In recent years, architects, regulatory bodies, and city planners have adopted several strategies for reducing solar heat gain. One of the simple strategies being the replacement of dark-colored surfaces that absorb sunlight with light color surfaces that reflect it [4].

Materials with a high Solar Reflective Index (SRI), also known as "cool" materials, reduce the solar heat gain on building roofs, public walkways, shading structures, and other surfaces [5]. Using cool materials proved to be a very cost-effective way to reduce building energy consumptions and also improves outdoor thermal comfort. Henceforth, these materials are encouraged by green building rating systems around the world and 
are being mandated by the governments [6]. The opportunity to accrue benefits from highSRI materials is even greater in hot and arid environmental conditions, such as UAE. However, a material's SRI value can change after installation and exposure on the site. This is typically due to diminished reflectance values, but emittance values can also vary [7]. Several studies reveal that the solar reflectance of roof coating is more dynamic and reduced by the soiling accumulation on the surface after naturally weathering due to outdoor exposure [8,9]. Studies shown solar reflectance attenuation due to soiling is the most important factor to determine the long-term performance of the white cool roof coatings [10].

Studies show that 'Cool coatings' present superior thermal performance and their application to the urban environment has greater potential in reducing surface temperatures with increased reflectivity [11]. The long-term benefit of cool coatings is, therefore, frequently reduced by a reduction in the solar reflective index in the first few years of onsite exposure, mainly through the build-up of dirt, dust, and microorganisms in biofilms [12]. However, the authors concluded that the effect of weathering even for a short period (3 months) caused degradation in reflectivity of coatings and therefore suggested choosing coatings with good 'dirt pick-up' and weathering resistance. Also, within the first year of exposure, a decrease in solar reflectance of $4 \%$ to $23 \%$ was observed for white polyvinylidene fluoride coated steel roofs exposed at different sites with varying precipitation and wind conditions [12]. Another study showed that panels with high-reflectivity paint lost $10-20 \%$ of that property within several months of exposure revealing that the degradation of the paint surface was mainly due to airborne contamination that cannot be neglected [13]. Further, the reduction in energy savings due to soiling estimated to be between $10-20 \%$ [14, 15]. Researchers also observed that the higher intensity of solar radiation, associated with high precipitation, compromises the integrity of the paint film and would favor the degradation of the outer paint surfaces [16]. Therefore, to realize the full potential of energy savings of the cool coatings, they must maintain high solar reflectivity for the service life of those coatings [17].

Cyclic maintenance thorough cleaning of cool coatings shown to restore $90 \%$ of the initial value of reflectance but the restoration of full energy savings is only temporary as soiling continues with exposure [18]. The most important consideration for cleaning is the labor costs, which are significant compared to returns on energy savings [14]. However, studies have shown that cleaning might be necessary to meet the potential of the cool roof's energy efficiency [17]. The Cool Roof Rating Council (CRRC), USA determined that SRI should be evaluated at the beginning and after 3-years of natural exposure to ascertain cool roof efficacy. This 3-year time period was recommended by most cool coatings manufacturers between the cleaning procedures and adapted by other major certification bodies such as Energy Star and European Cool Roof Council (ECRC) [19]. However, this requirement of periodic maintenance varies based on location and depends on numerous factors such as building characteristics, the specific type, and the properties of the coating.

Many previous research studies discussed above to determine the effect of natural aging on reflectance and emittance values were conducted in the USA, and few studies in southern Europe, East Asia and Brazil. However, there are no such studies found in the literature for naturally weathered cool reflective surfaces in the Middle East region. Therefore, we aimed to determine the long-term performance of high solar reflective index white paint surfaces exposed for three years in UAE whose climatic conditions mimic many locations in the region. Our study involves the evaluation of environmental stresses that adversely affect the important performance properties of those materials which otherwise expected to function for longer lifetimes even with harsh outdoor exposure conditions. A weathering test farm was developed in Ras Al Khaimah, UAE, and operated as an exposure site which was fully equipped with appropriate meteorological, radiometric instrumentation, and data acquisition capability. The study presents a precise and detailed knowledge of specific environmental conditions experienced by various weathered 
samples to understand location-specific performance losses and predict the long-term durability of the candidate solar reflective paints or coatings.

\section{Materials and Methods}

Three white high SRI paint-coated samples with high reflectance $(>0.85)$ and emittance $(>0.86)$ were acquired from the manufactures in the UAE market and were used as model "cool surfaces" to study their natural aging. The application and curing methods of sample paint panels were accomplished at the factory. Each coating/paint manufacturer prepared a total of 12 paint panels and they were responsible for ensuring the consistent application of the product coatings on the substrate provided. To maintain consistency in testing comparison, all coatings were applied on standard aluminum panels (3003 H14) [20]. All panels prepared for testing were applied with a dry film thickness or coverage recommended by respective manufacturers based on the use of the coatings in real applications. Preliminary non-destructive testing of the panels shown that the dry film thickness of paint panels was within $10 \%$ of the manufacturer's recommended minimum coating thickness. After the application of the paint, the panels were delivered to the site location. After initial testing three panels were kept in the lab as a reference and the remaining 9 panels from each manufacturer were exposed externally at the natural weathering farm in Ras Al Khaimah City (Figure 1) (2540 N, 5546 E, March 2017 to February 2020).
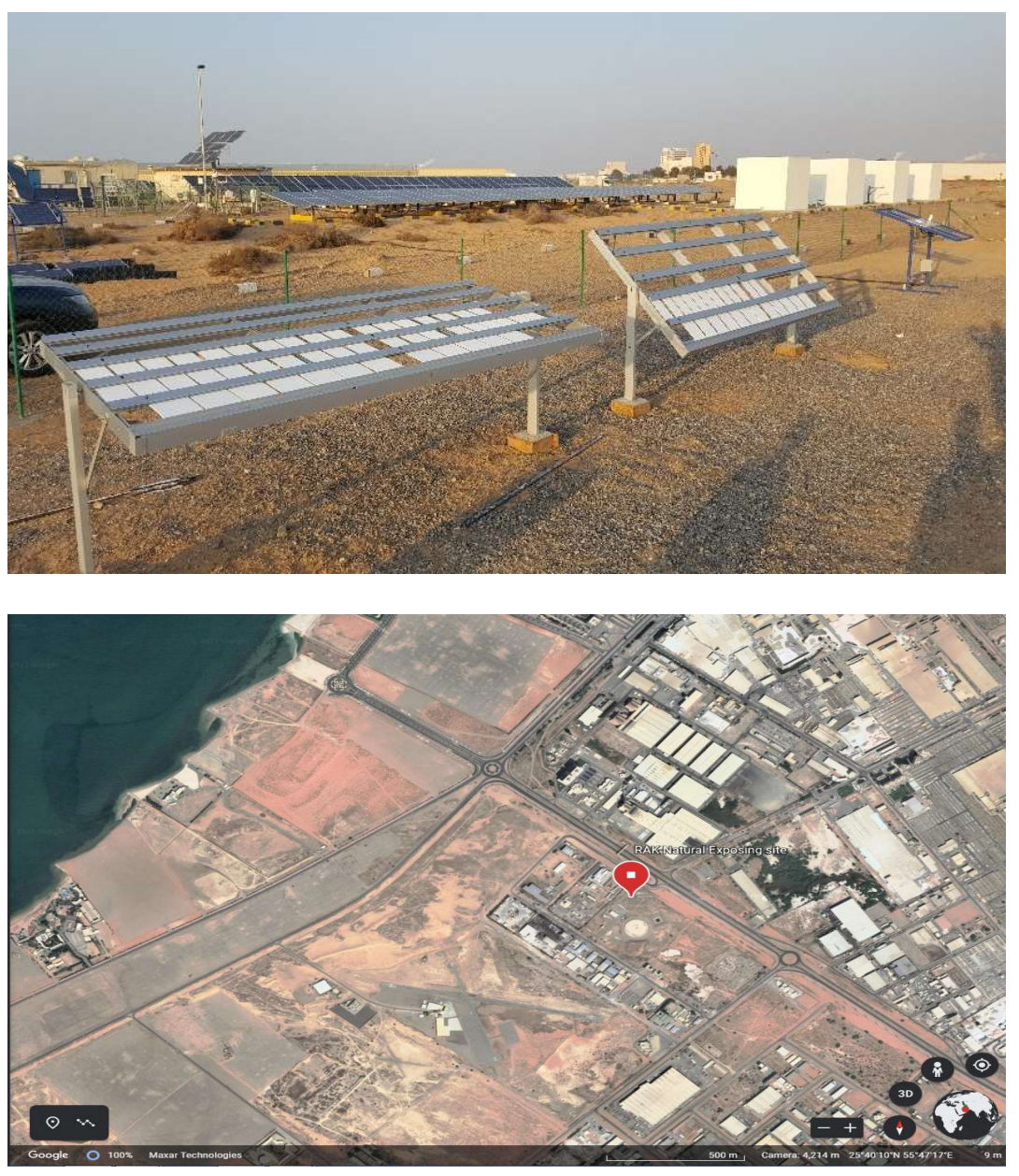

Figure 1. Natural weathering/aging site: Ras Al Khaimah, UAE [22]

Sample panels of each product were exposed for a minimum of three (3) continuous years and few sample panels remain untouched for that period and other panels were used for periodic evaluations. Samples were exposed as per ASTM G7/G7M-13 [21]. The 
samples were docked in $5^{\circ}$ and $45^{\circ}$ tilted racks as shown in Figure 1 . The exposure site lies within the premises of RAK Research and Innovation Center, AURAK, about $100 \mathrm{~m}$ from a highway and at a distance of $1.75 \mathrm{~km}$ from the sea coastline [22].

As mentioned earlier, natural weathering involves exposure to harsh outdoor conditions and analysis of meteorological and radiometric factors that affect the essential performance properties of the exposed materials. During the outdoor exposure period, the physical and/or chemical damage of the coatings might be induced by sunlight, especially the UV part of the spectrum, temperature, moisture, pollution, and wind. Solar radiation results in thermally-induced degradation through direct heat and defects can be observed at elevated temperatures. Precipitation, relative humidity in the atmosphere can accelerate hydrolytic reactions and result in morphological structural changes of materials. Further, harmful pollutants such as particulates, NOx, SOx, salts, and acid rain could also induce materials degradation through corrosive, oxidation reactions. Changes in the wind conditions alter the surface temperatures through convective heat transfer and may also result in the concentration changes of moisture and/or pollutants on the material surface [23].

The natural weathering exposure facility was a unique setup in the desert land of Ras Al Khaimah (RAK) free from residential pollution and urban structures. Compared with benchmark exposure sites (in the USA, Europe) shown in Table 1, RAK experiences high temperature, low rainfall, and high dusty conditions which might significantly affect the performance of coatings in a long run. Further, RAK has a humid and high UV radiation environment, suitable to test and analyze the natural weathering performance of exterior coatings or paints. Testing under these conditions could mimic extreme weather conditions of many parts of the Gulf cooperation council (GCC) region.

Table 1. Weather parameters of RAK test site compared with benchmark locations

\begin{tabular}{|c|c|c|c|c|}
\hline Weather Parameters & $\begin{array}{c}\text { Arizona }{ }^{(24)} \\
\text { (Phoenix) }\end{array}$ & $\begin{array}{c}\text { Florida }{ }^{(24)} \\
\text { (Miami) }\end{array}$ & $\begin{array}{c}\text { Sanary }{ }^{(24)}, \\
\text { France }\end{array}$ & $\begin{array}{c}\text { Ras-Al- } \\
\text { Khaimah }\end{array}$ \\
\hline Elevation & $1055 \mathrm{ft}$ & $10 \mathrm{ft}$ & $2001 \mathrm{ft}$ & 5 Feet \\
\hline Average total Solar Irradiance/year & $8004 \mathrm{MJ} / \mathrm{m}^{2}$ & $6588 \mathrm{MJ} / \mathrm{m}^{2}$ & $5500 \mathrm{MJ} / \mathrm{m}^{2}$ & $8,375 \mathrm{MJ} / \mathrm{m}^{2}$ \\
\hline Average total UV radiation/year & $334 \mathrm{MJ} / \mathrm{m}^{2}$ & $280 \mathrm{MJ} / \mathrm{m}^{2}$ & $382 \mathrm{MJ} / \mathrm{m}^{2}$ & $331 \mathrm{MJ} / \mathrm{m}^{2}$ \\
\hline Avg. Maximum Summer Temperature & $39^{\circ} \mathrm{C}$ & $34^{\circ} \mathrm{C}$ & $23^{\circ} \mathrm{C}$ & $43^{\circ} \mathrm{C}$ \\
\hline Avg. Maximum Winter Temperature & $26^{\circ} \mathrm{C}$ & $20^{\circ} \mathrm{C}$ & $9^{\circ} \mathrm{C}$ & $26^{\circ} \mathrm{C}$ \\
\hline Average Humidity & $49 \%$ & $80 \%$ & $76 \%$ & $58 \%$ \\
\hline Average Annual Rainfall & $186 \mathrm{~mm}$ & $1420 \mathrm{~mm}$ & $700 \mathrm{~mm}$ & $113 \mathrm{~mm}$ \\
\hline Coarse Particulate Matter PM10 $(25,26,27)$ & $183 \mu \mathrm{g} / \mathrm{m}^{3}$ & $54 \mu \mathrm{g} / \mathrm{m}^{3}$ & $30 \mu \mathrm{g} / \mathrm{m}^{3}$ & $157 \mu \mathrm{g} / \mathrm{m}^{3}$ \\
\hline
\end{tabular}

\subsection{Metrological data}

The meteorological data were obtained using automatic weather stations, installed next to the naturally exposed paint panels at the test site. Continuous measurements were obtained for air temperature, global solar radiation, and air relative humidity, using the monthly averages. The measurements obtained at the test site used the following equipment: for air temperature and relative humidity a Rotronic probe, model HC2-S3; for global solar radiation an Eppley Pyranometer, model CMP11 and for solar total UV radiation, an Eppley Radiometer, model TUVR. For rainfall precipitation, we used the data from our weather station and accumulated as total of each month. For PM10 dust concentrations, we used the data recorded by the National center of metrology (NCM) from the nearest weather stations [26].

\subsection{Reflectance and Thermal Emittance measurement with portable reflectometer}

Reflectance was measured according to ASTM C 1549-15 using a portable Solar Spectrum Reflectometer, model SSR -ER, Version 6.4 (Devices and Services Company, USA) 
[28]. Thermal emittance was measured using an Emissometer Model AE1-RD1 (Devices and Services Company, USA according to ASTM C 1371-10 [29]. Adequate time between measurements was maintained between samples to allow cooling of the surfaces for thermal emittance measurements. As shown in Figure 2, measurements were taken at three points on each panel (top, middle, and bottom), giving a total of 9 measurements for all three manufacturer panels naturally aged at the site for the three years. The reflectance and emittance measurements were carried out before exposure, periodical measurements for every 6 months, and final measurement after 3 years.

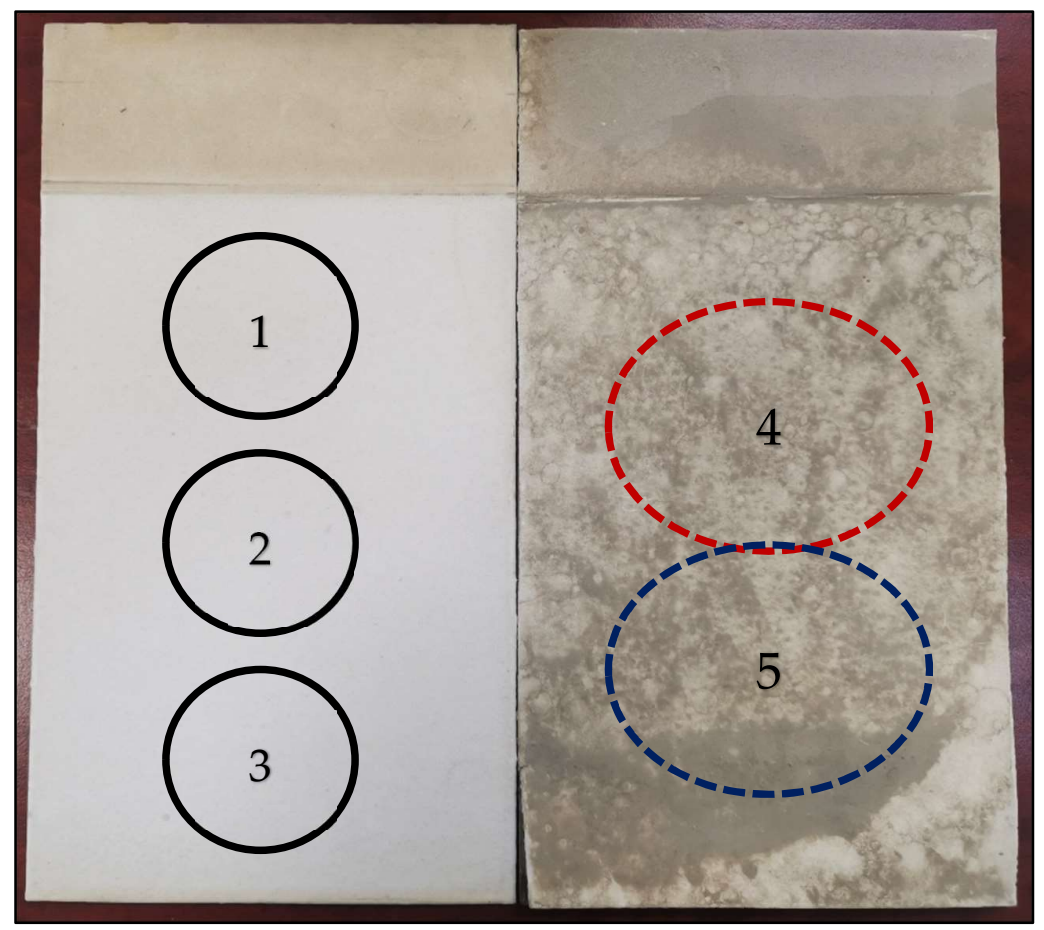

Figure 2. Panels showing three areas $(1-3)$, where reflectance and emittance were analyzed and two dashed areas $(4,5)$ where color analyses were carried out.

\subsection{Solar reflective index (SRI)}

The Solar Reflective Index (SRI) was calculated based on the procedure described in ASTM E 1980-11 [30]. Given the solar reflectance and thermal emissivity of a test surface, SRI was calculated for three convective coefficients $\left(h_{c}\right)$ of $5,12,30 \mathrm{~W} / \mathrm{m}^{2} \cdot \mathrm{K}$ (Eq.1), corresponding to low, medium, and high wind conditions, respectively. The following equation was used to calculate SRI:

$$
S R I=123.97-141.35 \chi+9.655 \chi^{2}
$$

Where

$$
\chi=\frac{(\alpha-0.029 \varepsilon)\left(8.797+h_{c}\right)}{9.5205 \varepsilon+h_{c}}
$$

$\alpha=$ Total solar absorptance $=1-$ solar reflectance

$$
\varepsilon=\text { Thermal emittance }
$$

The calculated SRI values were assessed based on the criteria established by the regional green building regulation and certification authorities having requirements and guidelines broadly similar to those in other parts of the world such as the USA, Europe, Australia, Brazil, Japan, China, India, and across the Middle East. The U.S. Energy Star 
Program, the California Energy Code Title 24, and European national codes have comparable requirements, as do voluntary green building rating programs - such as LEED and Green Star (Australia). ASHRAE Standard 189.1, 90.1 and the International Green Construction Code (IGCC) both recommend high SRI values, especially for hot climates. Accordingly, UAE regulators have set mandates and guidelines promoting cooler materials, with the most important summarized in Table 2 [31].

Table 2. Requirements and guidelines for high SRI materials in UAE

\begin{tabular}{ll}
\hline Regulatory Body & SRI Value \\
\hline $\begin{array}{l}\text { Estidama Pearl Building/Villa rating system } \\
\text { "RE-2: Cool Building strategies" }\end{array}$ & SRI $\geq 78$ (Initial) \\
Abu Dhabi International Energy Conservation Code & SRI $\geq 64$ (3-year aged) \\
(AD IECC) & Or Solar Reflectance $\geq 0.55$ \\
& Thermal Emittance $\geq 0.75$ \\
& Equivalent to SRI of 60 (3-year aged) \\
Dubai Green Building Regulations & Steep sloped (>1.6): SRI $\geq 29$ (Initial) \\
304.01 Urban Heat Island effect “High SRI Roof” & Flat or low-sloped (<1.6): SRI $\geq 78$ (Initial) \\
\hline
\end{tabular}

\subsection{Periodic cleaning}

As discussed earlier, all major rating bodies; the U.S. Cool Roof Rating Council (CRRC), European Cool Roof Council (ECRC), and Energy Star, preferred to conduct natural weathering tests for at least for 3-years to demonstrate long-term performance. Importantly unwashed testing allows for analyzing the material's dirt pick-up, or soiling/dust accumulation - a factor difficult to test in a short-term laboratory test [31]. As discussed earlier, the energy savings from cool materials depends on solar reflectivity and maintaining the condition of the coated surfaces. Thus, periodic maintenance through cleaning the surfaces might be necessary to retain mainly the solar reflectance and to enhance the contribution to energy savings. A study in the USA employed a cleaning regime to retain initial solar reflectance of 0.70 and shown an increase in the net energy savings by over $40 \%$ [32]. Another 3-year exposure study in Italy suggested considering a cleaning program in Spring as a best practice as the soiling effects were higher in Winter and cleaning before the oncoming cooling loads of summer could maximize returns on investment [33].

In the current study, we incorporated a periodic cleaning program, and specimen surfaces were washed every 6 months (during Spring and Fall) to investigate the degradation in reflectivity due to soiling. Further, washing of the specimens conducted annually in Fall and Spring cycles as well to analyze the percentage retention of solar reflectivity. The washing process involves pressurized water spray without manual intervention to minimize damage to the coating while removing dust contamination. The coatings were then dried after washing at indoor temperature and the SRI values were determined.

\subsection{Infrared thermal imaging}

For higher emissivity surfaces such as the high SRI paints or coatings, reflected temperature might have less influence. However, in order to define the coatings as cool coatings or surfaces, it's important to know the surface temperatures during natural exposure. The ability to visualize the surface temperature gives infrared thermography a wide scope of application, particularly in the field of non-destructive testing [34]. In the building industry, thermography may be applied to many facets of building performance including the insulation defect detection. In this study, we performed thermal imaging of the samples exposed on the low slope and steep sloped racks to analyze the surface temperatures 
of the panels before and after washing. A Fluke Ti-45 thermal imager was used for obtaining the differences in surface temperatures of exposed and unexposed samples.

\subsection{Color difference}

The color was determined in two areas on the sample as shown in Fig.2, before and after washing of the samples exposed for 3-years and compared with the unexposed samples. BYK Gardner Wireless Color Measurement Device was used to determine $\mathrm{L} *, \mathrm{a} *, \mathrm{~b} *$. The value of $\mathrm{L} *$ varies from 0 to 100 (black to white), a* from negative (green) to positive (red), and $\mathrm{b} *$ from negative (blue) to positive (yellow) values. With these values, we could calculate the color difference $(\Delta E)$ through the Eq.(3).

$$
\Delta E=\sqrt{\Delta L^{2}+\Delta a^{2}+\Delta b^{2}}
$$

\section{Results and Discussion}

The results presented in this section cover the three years of natural weathering of high SRI white paints for exterior use, which were bought in the UAE market. This study was part of the research funded by the Abu Dhabi Quality and Conformity Council, UAE [35].

\subsection{Metrological data}

Figures 3 and 4 show the meteorological information measured at the test site and also data obtained from other sources during the experiment period in Ral Al Khaimah, UAE. Figure 3 presents the global solar radiation at the exposure site for the three years with an average of $638.3 \mathrm{~W} / \mathrm{m}^{2}$, with an average amplitude of $372 \mathrm{~W} / \mathrm{m}^{2}$.

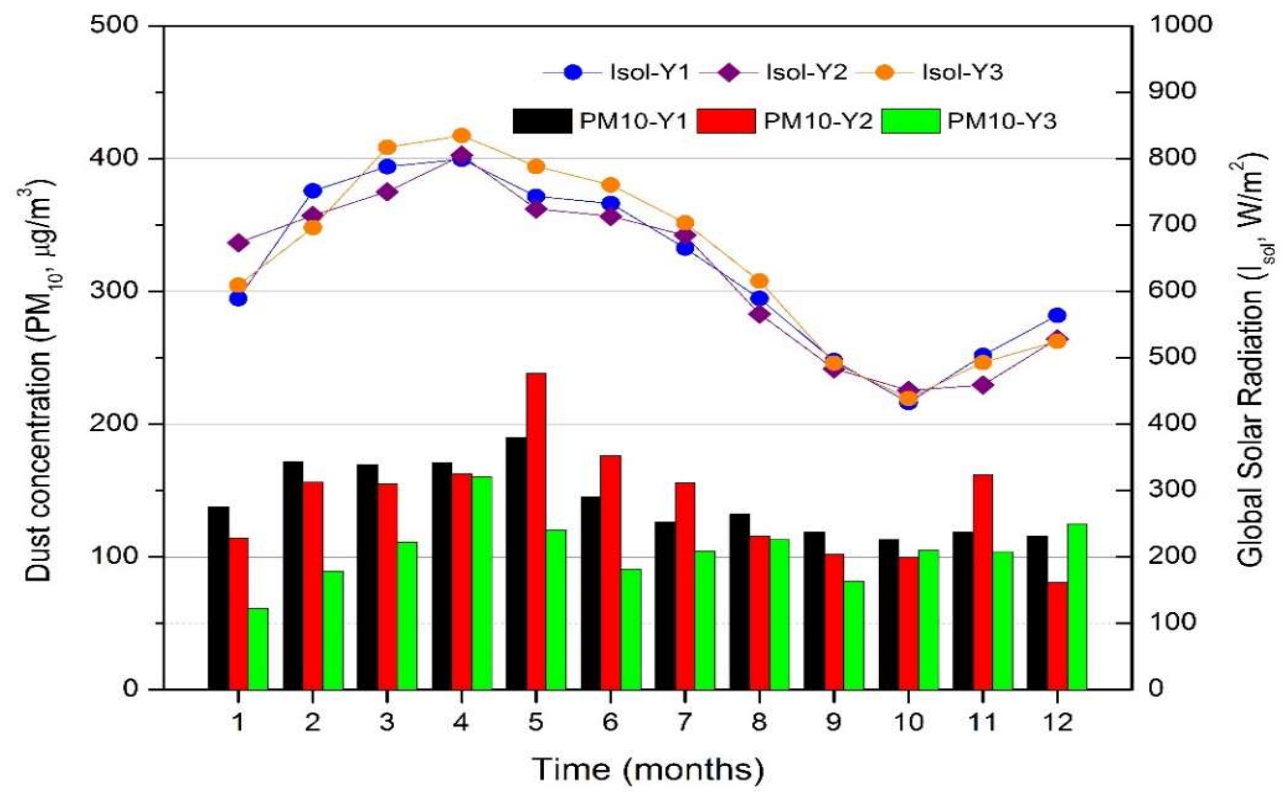

Figure 3. Solar radiation at site and Particulate matter (PM10) concentration at Ras Al Khaimah.

Figure 3 also shows the atmospheric PM10 data between 2017 and 2020, which accounts for average PM10 concentrations from the nearest measuring station in Ras al Khaimah, UAE according to reports by NCM (National Center for Metrology). Annual average concentrations of $130 \mu \mathrm{g} / \mathrm{m}^{3}$ were reported with amplitudes of $77 \mu \mathrm{g} / \mathrm{m}^{3}$ in the first year, $157 \mu \mathrm{g} / \mathrm{m}^{3}$ in the second year, and $99 \mu \mathrm{g} / \mathrm{m}^{3}$ in the third year respectively. The regime precipitation measured at the exposure site was quite distinct during the exposure period, both in volume and distribution over the three years. As shown in Figure 4, the average total rainfall at the site for 3 years is $112.6 \mathrm{~mm}$ with a total of $110 \mathrm{~mm}$ in the first 
year, $42 \mathrm{~mm}$ in the second year, and $186 \mathrm{~mm}$ in the third year respectively. Second-year of exposure has recorded the least precipitation and also high PM10 dust concentrations. The Third-year of exposure has the highest rainfall which would have a significant effect on reflectance measured at the end of 3 years period. Further, Figure 4 also presents the total UV radiation (TUVR) measured within the wavelength range of $285-395 \mathrm{~nm}$. Mean total UV radiation of $21.5 \mathrm{~W} / \mathrm{m}^{2}$ was recorded for the three years with an amplitude of 11 $\mathrm{W} / \mathrm{m}^{2}$ in the first year, $14.5 \mathrm{~W} / \mathrm{m}^{2}$ in the second year and $19.4 \mathrm{~W} / \mathrm{m}^{2}$ in the third year respectively.

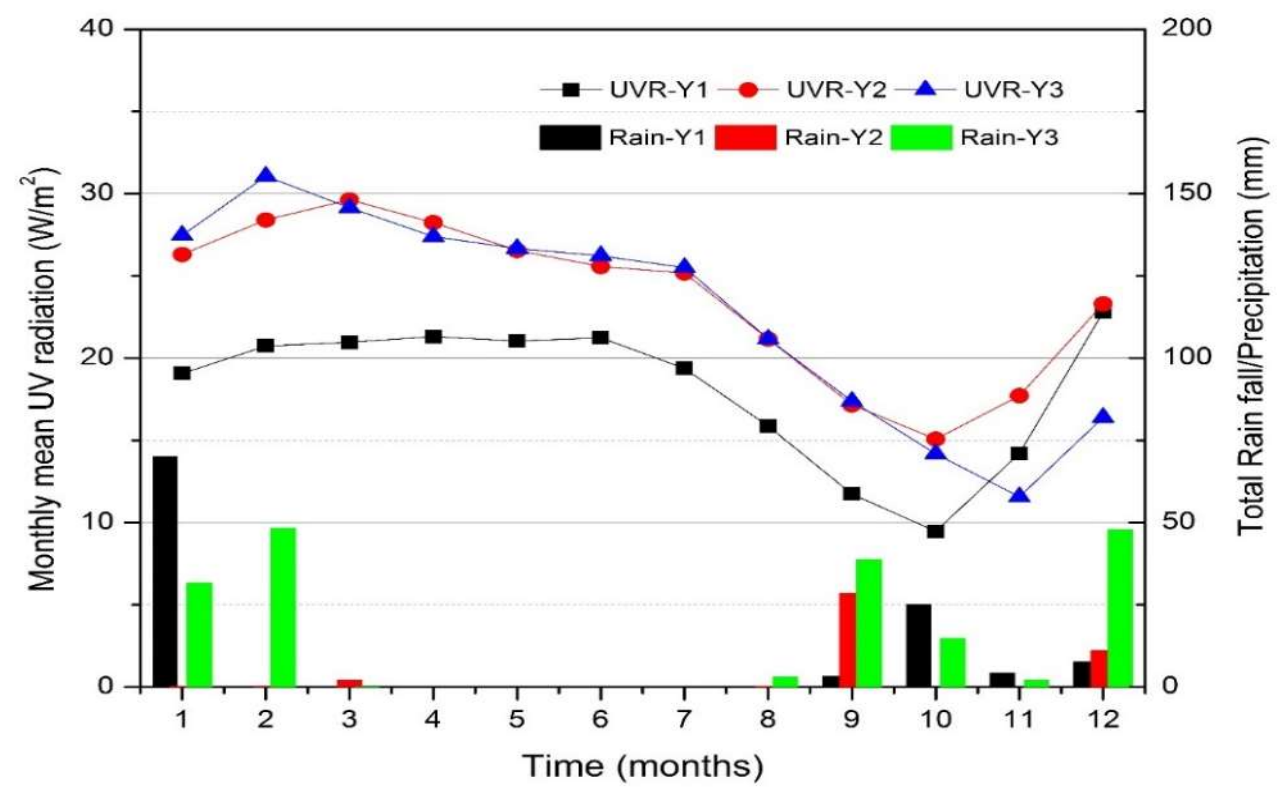

Figure 4. Precipitation and UV radiation data at Ras Al Khaimah, UAE

\subsection{Images after weathering/aging}

Figure 5 shows the images of the samples exposed at two different tilts from various manufacturers. As shown in the images, samples exposed at a low tilt (Figure 5a) show a high amount of dust accumulation owing to less runoff compared to the samples exposed at a higher tilt (Figure 5b).

The characteristics of the particulate matter, precipitation affect the macroscopic appearance of the dust and alters surface appearance. All the samples exposed also shown noticeable discoloration due to dust compared to the non-exposed samples. As evident from Figure 5, images reveal that there were obvious environmental influences, and the appearance of samples from M1 and M2 show less esthetic surface alterations, and less color difference (Figure 10) compared to M3 in terms of dust infusion or chalking. Samples of M3 exposed at $5^{\circ}$ tilt, became darker with high dust penetration, while the same samples at $45^{\circ}$ tilt did not blacken or discolored compared to others on the same tilt.

\subsection{Reflectance and Thermal Emittance}

As shown in Figure 6, the reflectance values tended to decrease sharply during the initial six months of exposure period and further appears as a sinusoidal wave until 3years of exposure period. The changes in reflectance of the panels were due to obvious environmental effects; high dust during summers and rainfall during the winters as shown in Figure 7 of next section. 


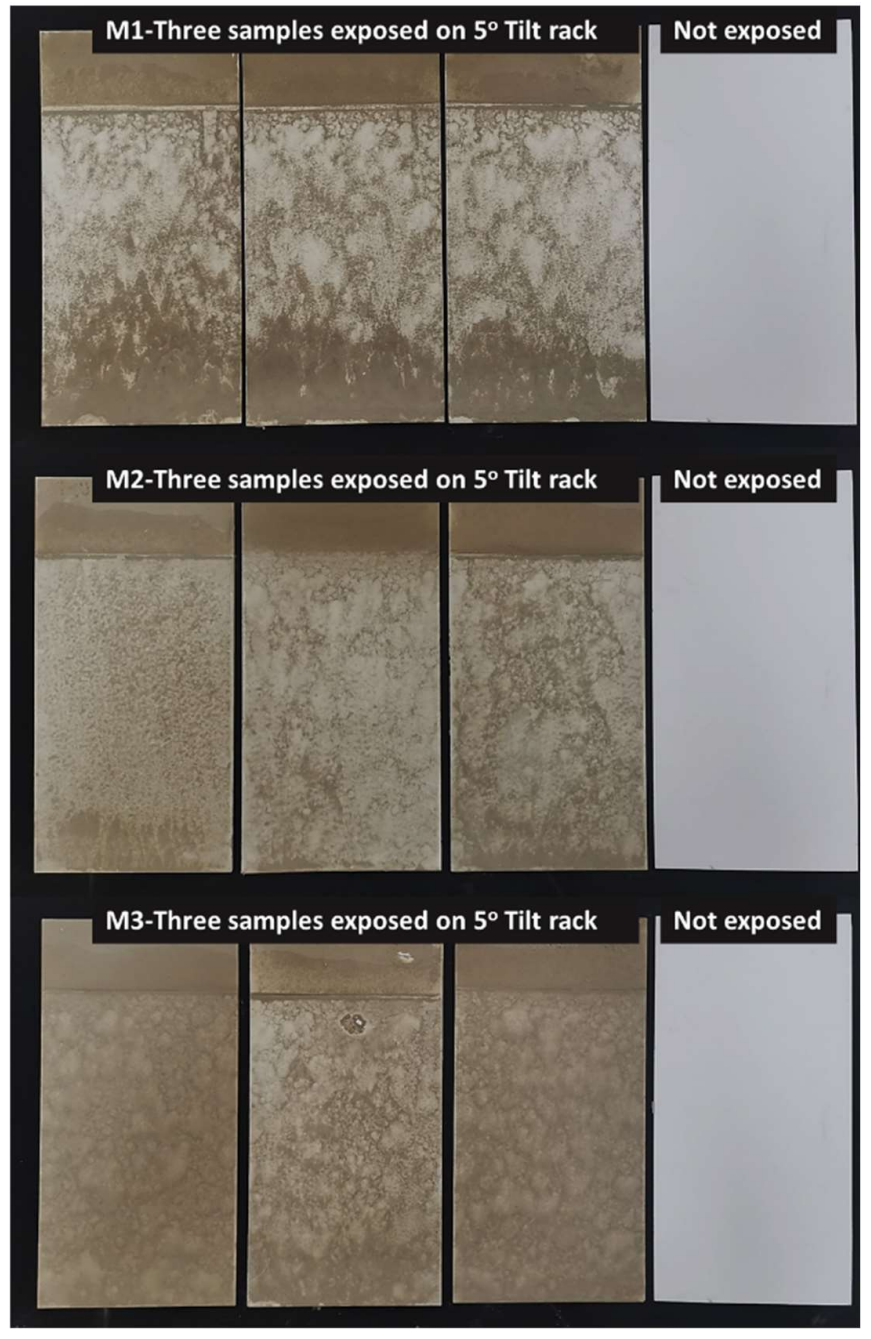

(a)

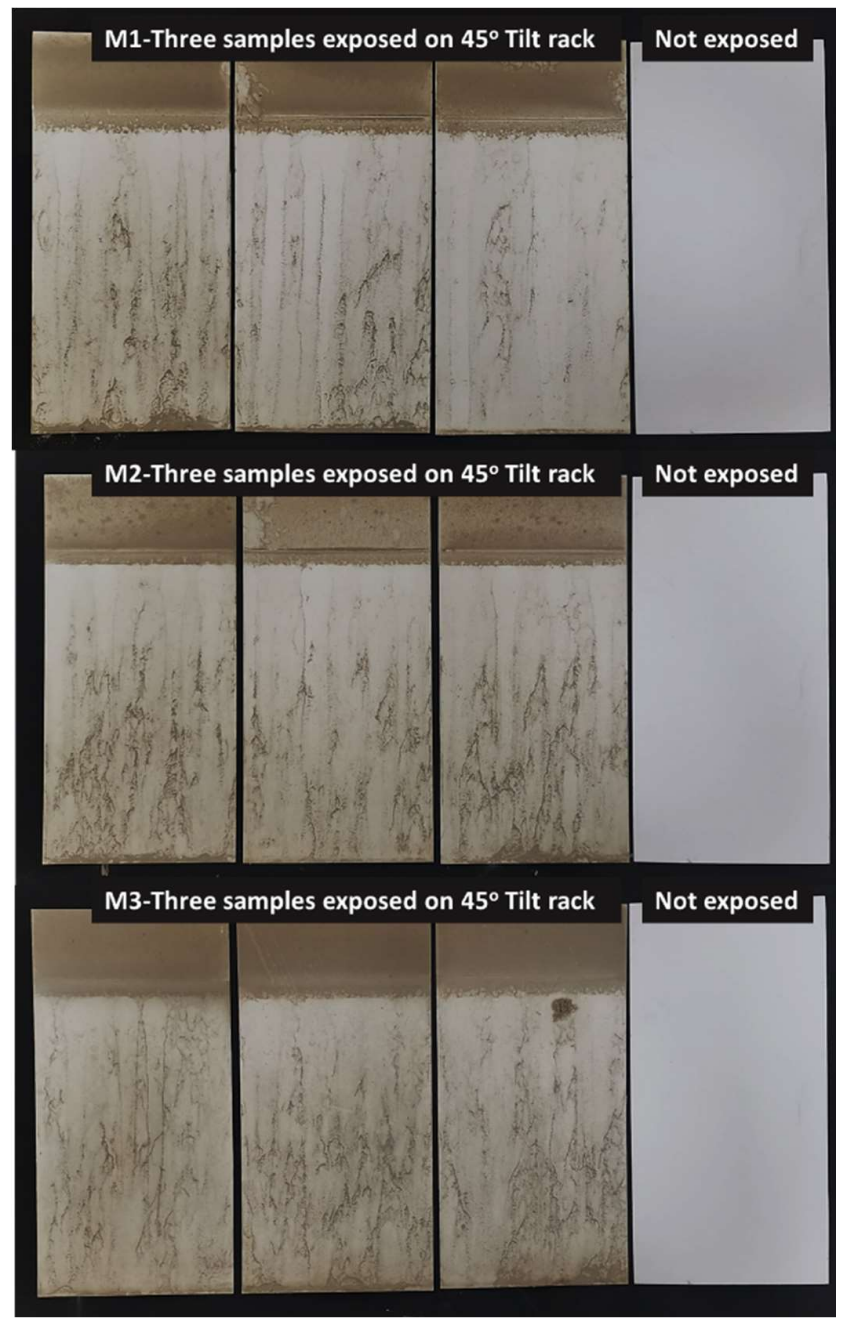

(b)

Figure 5. Triplicate samples of various manufacturers after 3-years of natural aging at Ras al Khaimah (a) $5^{\circ}$ tilt and (b) $45^{\circ}$ tilt

Samples of M3 exposed at $5^{\circ}$ tilt (Figure 6a), showed the greatest decrease in the reflectance in the initial 6-8 months and had least retention of reflectance value at the end of 3-year exposure period. Average reflectance value of M3 exposed on low tilt was 0.53 with an amplitude of 0.35 and for the higher tilt exposure, the average reflectance was 0.62 with a similar amplitude of low tilt samples. On the other hand, samples from M1 exposed at low tilt shown least decrease in reflectance values over the exposure period with average reflectance of 0.64 and amplitude of 0.38 . As shown in Figure 6, the variation in emittance is very little and almost constant with time of exposure in all samples, agreeing with results previously found in literature exposed at other parts of the world [16]. Emittance values remain almost constant (average $\approx 0.872$ ) over the period of exposure for all manufacturers concluding that reflectance contributes majorly for determination of SRI of coatings. However, thermal emittance is an important parameter due to its contribution to "urban heat island" effect and have greater impact on adjacent buildings. 


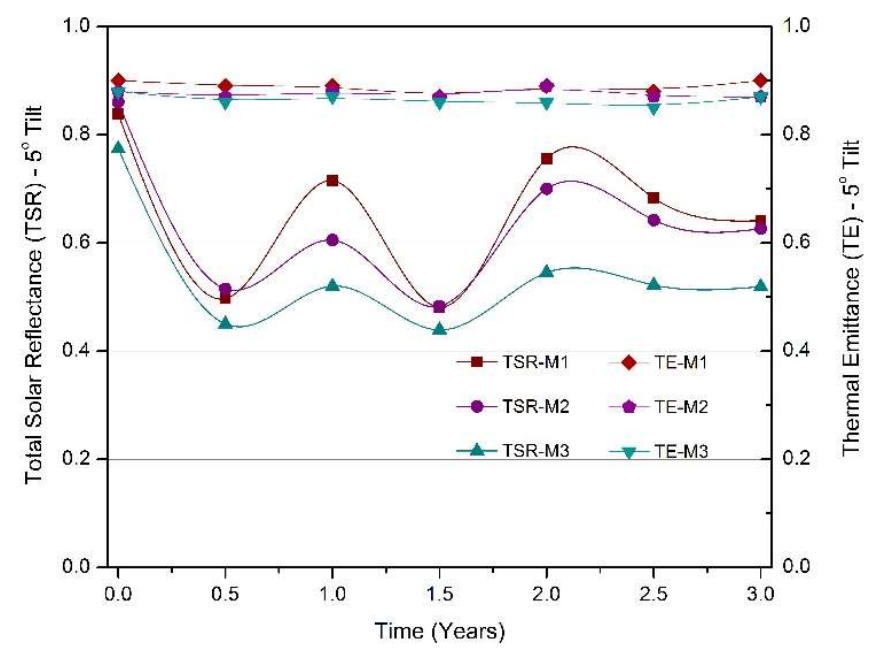

(a)

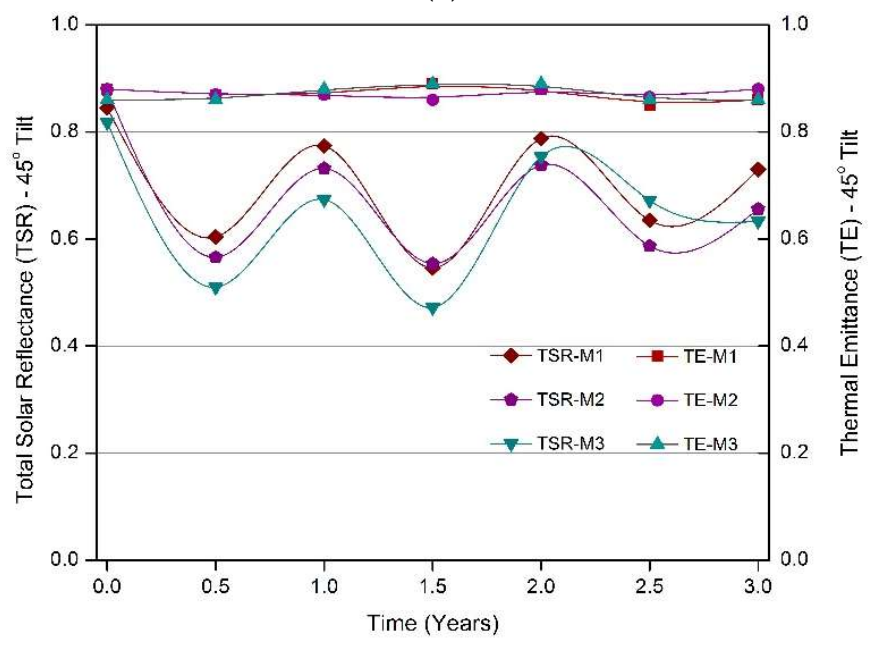

(b)

Figure 6. Reflectance and emittance as a function of exposure period at (a) $5^{\circ}$ tilt and (b) $45^{\circ}$ tilt

\subsection{Analysis of Solar reflective index}

Based on the calculation procedure in ASTM E 1980-11, the reflectance results were combined with emittance measurements to obtain the Solar Reflectance Index (SRI). Figure 7 presents the variation in SRI with exposure period and correlates with the environmental factors discusses earlier (dust and rainfall). The SRI after three years varied among all the manufacturers and varied based on the tilt of the racks they exposed. After 3-years exposure on low tilt, M1 showed the lowest decrease (26\%), M2 showed 30\% decrease, while M3 had the highest decrease (37\%), indicating a less tendency for panels of M3 to lose heat to the environment, compared to the other two. Similar trends observed for samples exposed on higher tilt with least decrease of $11 \%$ for $\mathrm{M} 1$ and highest decrease of $23 \%$ for M3. Results indicate that the average decrease in SRI values between low and high tilt exposed samples was $14.3 \%$. The ability to retain highest percentage of SRI on $45^{\circ}$ tilt exposed panels was due to less dust accumulation (shown in Figure 5) and high runoff due to the high rainfall in the final year of exposure period. As shown in Figure 7, with high $\mathrm{PM}_{10}$ concentrations during the mid of second year of exposure, the SRI values dropped significantly. With considerable amount of precipitation during 24-26 months, gain in SRI 
values was observed. More stability in the SRI values was observed during the third year of exposure owing to the balanced environmental conditions.

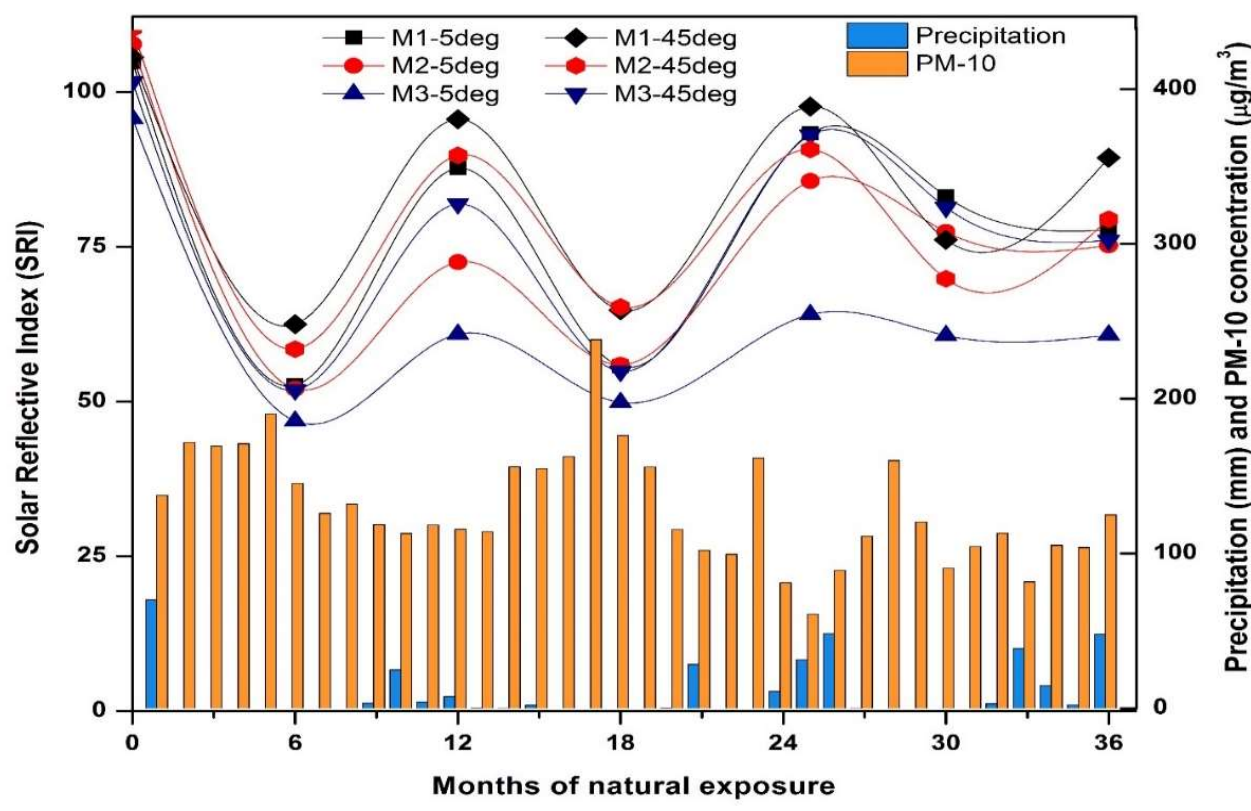

Figure 7. Solar Reflective index (SRI) as a function of natural weathering period

SRI values after 3-years exposure for roof coatings indicate that samples from M1 and M2 have SRI > 64 and they should be accepted as cool materials as per the guidelines of regulatory bodies. However, for the samples of M3, the SRI values fall below the requirement due to their inherent material properties. When compared with the manufacturer (M3) data of 3-year aged coatings in benchmark locations in USA, the observed SRI value lowered by $21 \%$. The results indicate the significance and necessity for regional weathering of cool materials, and which not only helps the authorities to regularize penetration of quality products into the market but also aid the manufacturers to tune their product to perform better in those harsh climatic conditions.

\subsection{Effect of periodic cleaning}

Figure 8 shows the fluctuation of SRI as follows: original reflectivity of panel (black bar), initial SRI values (yellow bar only), SRI values of exposed samples (yellow and blue bars combined) where blue shading indicates the change in reflectivity before and after washing. The specimens of various manufacturers are washed annually and the increase in SRI values were presented in the Figure 8. Observations show that, increase in SRI values during the second year washing cycle were least whereas highest increase in SRI values observed during the third year washing cycle. Therefore, adhesion of contaminants after 3-years of exposure may contribute to major degradation of the coatings. Also, trend show that samples exposed at higher slope or tilt has less increase in SRI values due to washing compared to samples exposed on low slope or tilt. After 3-years of exposure, the highest increase in SRI value due to washing (21\%) was obtained for M1 exposed at $5^{\circ}$ tilt and the least increase (9\%) was obtained for M3 exposed at $45^{\circ}$ tilt.

Figure 9 presents the retention of SRI values for cleaned and non-cleaned samples during the exposure period of 3-years with periodic washing cycles employed for every 6 months. With regular cleaning in place, the average retention of SRI values was stable over the exposure period for both high and low sloped exposures. At the end of three years exposure, for the unwashed samples, the average percentage retention of SRI values was $68.5 \%$ and $75.8 \%$ respectively for $5^{\circ}$ and $45^{\circ}$ tilt. Whereas employing periodic washing cycles, reduced the gap between these values from $7.3 \%$ to $1.6 \%$. 


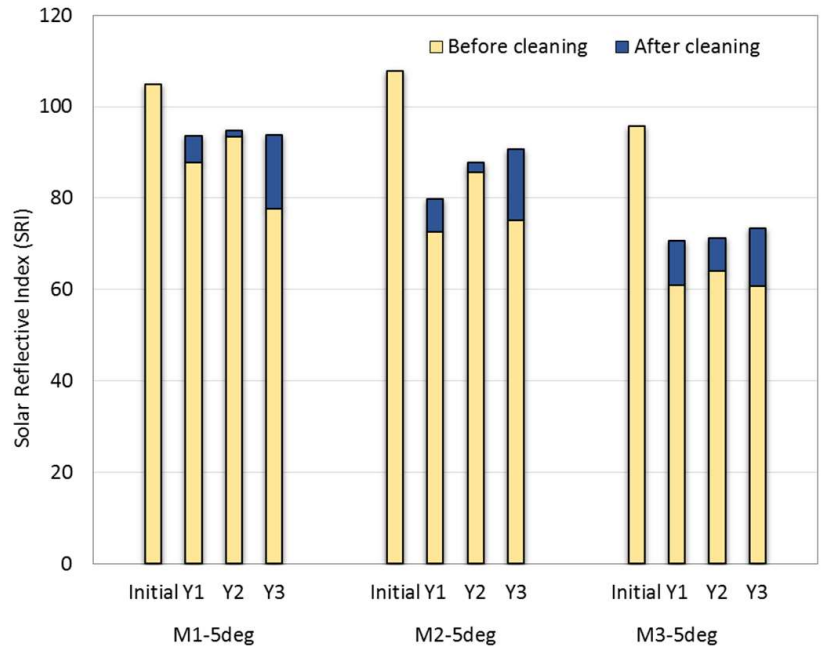

(a)

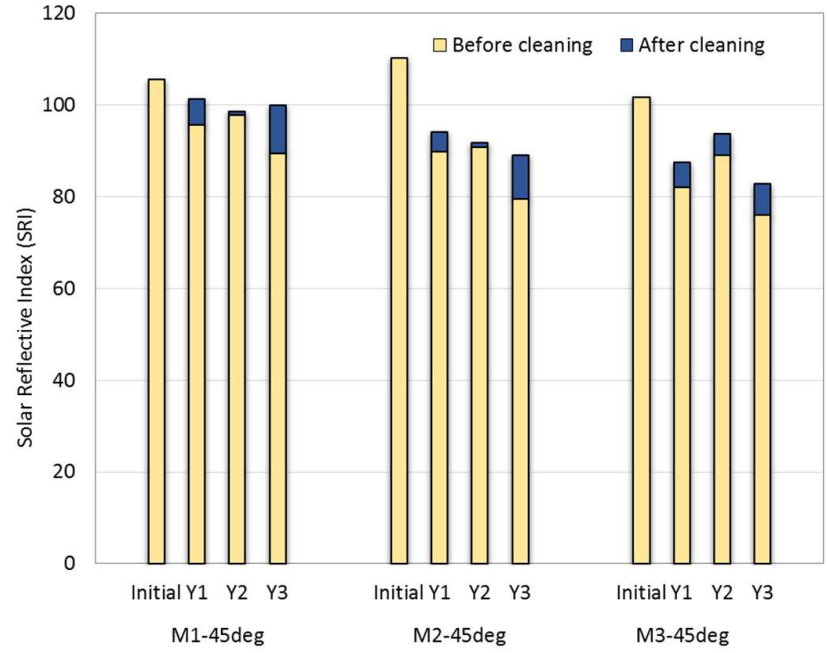

(b)

Figure 8. Effect of cleaning on solar reflective index (a) $5^{\circ}$ tilt and (b) $45^{\circ}$ tilt

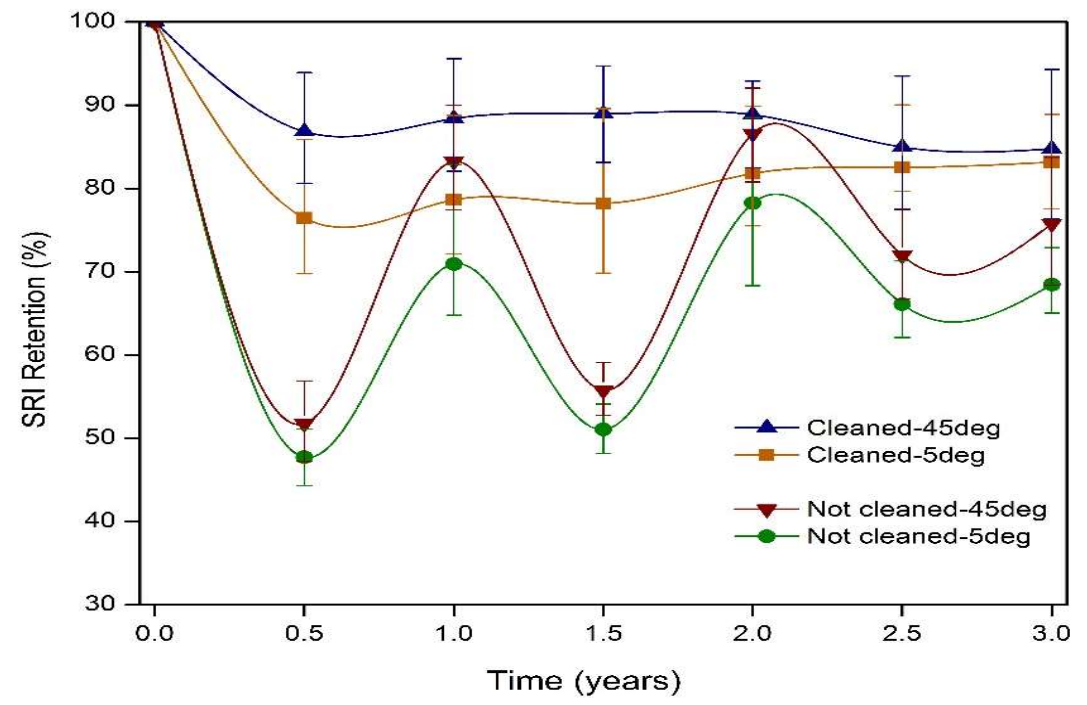

Figure 9. Percentage retention of SRI values as function of exposure period.

The results indicate the importance of washing cycles, especially for roof coatings. The issue of whether or not to permit "washing" of the sample has received much attention in the development of the CRRC's "aged test protocol". Current practice is to measure the radiative properties of exposed samples without cleaning in order to best reflect "realworld" conditions [36]. However, many regional manufacturers hold on to the "prowash" argument stating that (1) through washing, their materials can restore close to their initial solar reflectance values and (2) hence, washing should be encouraged by adopting it as a requirement in the region. In fact, the conditions of UAE are harsh compared to the benchmark location in the USA (Florida, Arizona) and concerns were raised by many manufacturers that their products could get surprisingly different results compared to weathering tests elsewhere. One study on 5 years aged reflective properties shows that simple washing with detergent and algaecide brought back $90 \%$ of their original reflectivity values [37]. Our findings prove the argument to be correct and show retention of 80- 
$90 \%$ of original values with regular (6 months) washing cycles. The hot conditions of UAE might prevent algae or fungal growth but the very dusty and sandy surfaces could be restored to normal conditions by employing simple washing cycles.

Further in order to determine the preferred season for the maintenance cycles, exposed samples were washed during both early Fall (September) and Spring (March) seasons in UAE and the percentage retention of SRI values are reported in Table 3.

Table 3. Retention of initial SRI values through annual maintenance (Fall and Spring)

\begin{tabular}{ccccccccc}
\hline \multirow{2}{*}{$\begin{array}{c}\text { Expo- } \\
\text { sure Tilt }\end{array}$} & $\begin{array}{c}\text { Manu- } \\
\text { facturer }\end{array}$ & \multirow{2}{*}{ Initial SRI } & \multicolumn{3}{c}{ Washed during Fall } & \multicolumn{2}{c}{ Washed during Spring } \\
\cline { 4 - 8 } & & Year-1 & Year-2 & Year-3 & Year-1 & Year-2 & Year-3 \\
\hline \multirow{2}{*}{ Low } & M1 & 104.83 & $87 \%$ & $89 \%$ & $90 \%$ & $89 \%$ & $88 \%$ & $90 \%$ \\
slope (5) & M2 & 107.74 & $72 \%$ & $73 \%$ & $81 \%$ & $74 \%$ & $72 \%$ & $85 \%$ \\
& M3 & 95.72 & $72 \%$ & $75 \%$ & $73 \%$ & $74 \%$ & $68 \%$ & $80 \%$ \\
High & & & & & & & & \\
slope & M1 & 105.63 & $94 \%$ & $95 \%$ & $94 \%$ & $96 \%$ & $94 \%$ & $95 \%$ \\
$\left(45^{\circ}\right)$ & M3 & 110.28 & $84 \%$ & $87 \%$ & $88 \%$ & $85 \%$ & $81 \%$ & $83 \%$ \\
\hline
\end{tabular}

The maximum average difference in SRI retention during the two seasons observed to be $3 \%$ with the lowest retentions shown during the Fall washing cycle. This is due to the high soling of the surfaces in Summer and high precipitation during winter enhanced SRI retention values during the Spring washing cycle. However, if only annual cleaning is employed, it's preferred to clean during the Fall cycle to ensure consistent energy savings. The finding is in contrast to the literature study preferring Spring washing cycle in Italy [33].

\subsection{Thermal imaging for surface temperatures}

As mentioned earlier, infrared thermal imaging was used to investigate the temperature on surface of the paint surfaces and to understand the differences in their thermal performance. Figure 10 presents a visible and an infrared image of the three selected manufactures coatings exposed on $5^{\circ}$ tilt.

The surface temperatures were measured during midday hours and compared for these sample before and after washing at the end of 3-year exposure period. It was found that the sample temperatures were quite uniform on the test surface, but small temperature gradients were present around the edges of the samples influenced from their surroundings. A very important factor regarding the thermal performance of coatings is "dirt pick-up" resistance. As shown in Figure 10b, there was degradation in the thermal performance of tested samples indicated by increase in surface temperatures compared to the unexposed cool coating. The higher the dust pick-up resistance the lower is the temperature difference between exposed and unexposed samples (as in the case of M1 in Figure 10) indicating better reflection and thermal performance. All the exposed washed or unwashed paint panels in the study, were characterized by higher surface temperatures than the surface temperature of unexposed samples. The coolest coatings were from M1 which are $9.6^{\circ} \mathrm{C}$ warmer than unexposed samples, while the samples from $\mathrm{M} 3$ were $10.2^{\circ} \mathrm{C}$ warmer. Further washed samples after 3-years of exposure shown significant improvement in thermal performance with decrease in average surface temperatures by $7.2^{\circ} \mathrm{C}$. When compared with the unexposed samples, the washed panel's surface temperature difference with respect to unexposed panels was ranged between 2.7 and $4.7^{\circ} \mathrm{C}$. Even though all washed coatings under study are of the same water based acrylic paint type, they experienced differences in mean surface temperatures caused by differences in their reflectance, discoloration and dust penetration which was clearly visible in Figure 10a (lower image). 


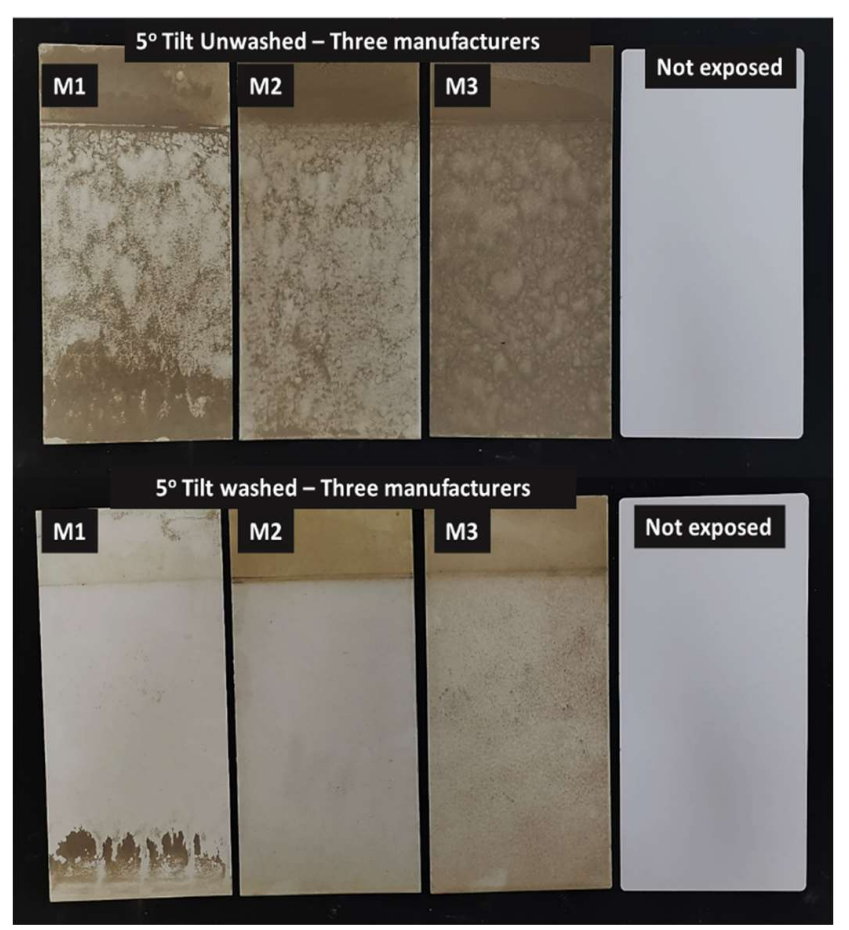

(a)

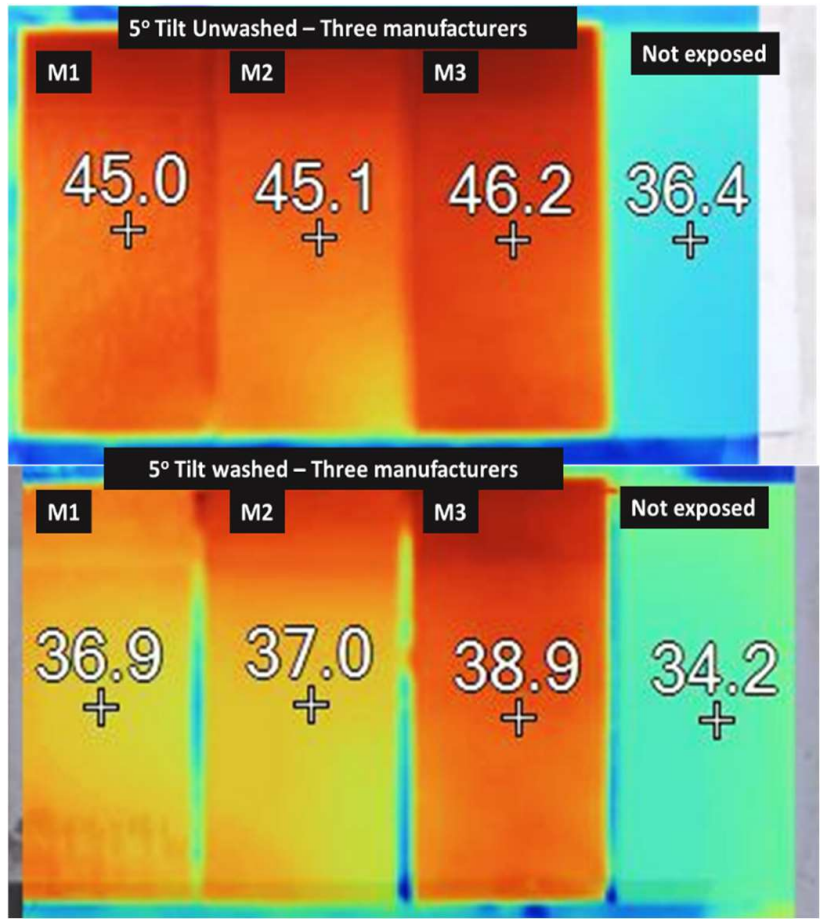

(b)

Figure 10. Unwashed and washed visible (a) and infrared (b) images of the three selected samples

\subsection{Color difference and reflectance}

The results presented in Figure 11 show the reflectance as a function of color difference $(\Delta \mathrm{E})$ after 3 years of exposure. In general, the decrease in reflectance inversely proportional to the increase in color difference (Figure 11a). For the samples exposed on low slope rack, the color difference of unwashed samples at the end of exposure period ranged between 20 and 32, while the samples exposed on steep slope exhibits color difference range between 7.8 and 22.6. Sample of M3 placed at 5o tilt had the highest color difference whereas sample of M1 placed at 45o tilt has least color difference values.

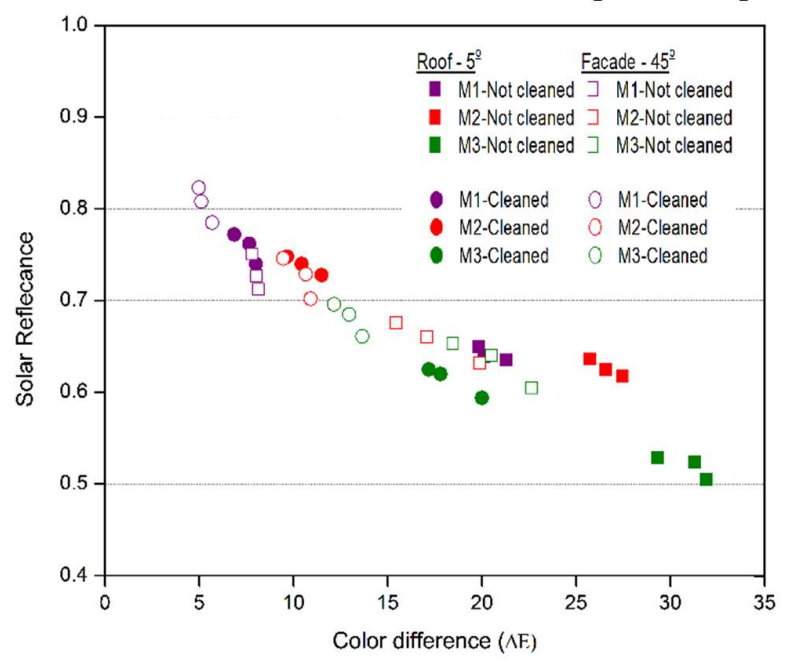

(a)

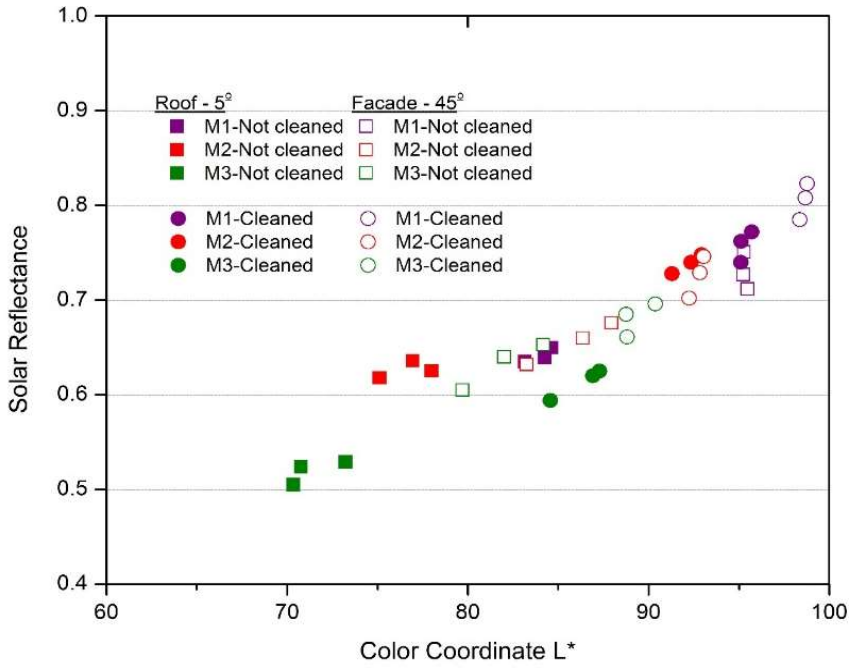

(b)

Figure 11. Solar reflectance plotted against (a) color difference $(\Delta \mathrm{E})$, coordinate $\mathrm{L} *$ 
Further, washing the samples after three years of exposure significantly decreased the color difference with respect to unexposed original samples. The color difference of washed samples ranged between 6.8 and 20 for low slope exposed samples while the values were ranged between 5 and 13.6 for high slope exposed samples. The decrease in the L* co-ordinate (White $=100$ and black $=0$ ) follows an opposite pattern compared to the color difference. The decrease of $\mathrm{L} *$ was directly proportional to reflectance decrease, indicating darkening of the surface due to contamination reduced the reflectance (Figure 11b). Coordinate a*, shows tendency from green (negative) to red (positive). All washed and unwashed samples exposed on low slope shown values below 5 whereas samples on the high slope have values recorded below 2. Further the results confirm that the blackening of the surface (coordinate $\mathrm{L} *$ ) was more significant for decreasing reflectance in comparison with co-ordinate $\mathrm{a}^{*}$. On the other hand, variation between 6 and 12 for low sloped samples and from 5 to 10 for high slope exposed samples (least for washed and highest for unwashed) observed for coordinate $b *$ (blue-yellow). These values indicate a slight yellowing tendency, after 3 years of exposure. The yellowing observed during outdoor exposure might be associated with the high UV irradiance, which might have resulted in photo-oxidative degradation and discoloration of polymers [38]. Although all coordinates showed some correlation with reflectance, the color difference, $\Delta \mathrm{E}$, and the black-white coordinate, $\mathrm{L} *$, correlations are most significant consistent with the results from other studies in the literature [16].

\section{Conclusions}

After careful observation of the results, all the tested samples could be termed as cool materials owing to their high SRI values which are greater than 95. Every paint sample could be eligible for use in Green ratings according to the regulators in UAE owing to their high initial SRI values. However, it's apparent from our research that the long term performance of these materials might get compromised due to extreme weather conditions of UAE. Important radiative property to be maintained for long-term performance is solar reflectivity rather than thermal emittance. The rate of reduction in radiative properties was analyzed using the periodic measurements and estimated to be between 15$35 \%$ (depend on the manufacturer's material properties) over a 3-year period of exposure. Weather factors such as high temperature, UV radiation, low rainfall, and dust concentrations in UAE might not favorable for the long-term durability of the paints/coatings tested and passed as cool materials which are exposed at benchmark locations around the world. In order to develop quality reflective paints suitable for the region or to penetrate into the market, we stressed the importance of testing the products in the real regional climatic conditions. The periodic unwashed and washed evaluations for the SRI values provided greater insights into SRI retention of such coatings through maintenance cycles over a period of time. We recommended an annual cleaning of roof coatings preferably during the Fall season to ascertain balanced SRI values over a year along with $10-20 \%$ overall improvement when compared with unwashed exposures. Thermal imaging and color difference measurements provided greater insights into soiling and dust penetration into coated surfaces. Manufacturers must also need to consider testing different formulations with dust repellence or low elongation properties. As the aged testing requirement not mandated by the authorities in the region to qualify cool materials, we believe that our research study would accumulate knowledge for drafting aged testing protocol in this region and aid in developing mandates by the regulatory bodies to encourage penetration of quality products. The research study also benefits manufacturers, consultants, energy practitioners to set high standards and encourage innovations to fine-tune their products for enhanced performances.

Author Contributions: N. T. Uday Kumar: Conceptualization, Funding acquisition, Project administration, Formal analysis, Writing - original draft, Writing - review \& editing. Waqar Ullah: 
Investigation, Formal analysis, Resources planning, Visualization, supervision, Writing - original draft, Writing - review \& editing. All authors have read and agreed to the published version of the manuscript.

Acknowledgments: The authors would like to thank Abu Dhabi Quality and Conformity Council $(A D Q C C)$ for providing funds to develop the natural weathering farm. We extend our thanks to $D r$. Simon Miller form QCC for his technical, administrative support during execution of the project.

Conflicts of Interest: The authors declare that they have no known competing financial interests or personal relationships that could have appeared to influence the work reported in this paper. Also, the funders had no role in the design of the study; in the collection, analyses, or interpretation of data; in the writing of the manuscript, or in the decision to publish the results".

\section{References}

1. Akbari, H.; Cartalis, C.; Kolokotsa, D.; Muscio, A.; Pisello, A. L.; Rossi, F.; Santamouris, M.; Synnef, A.; Wong, N. H.; Zinzi, M.; Local climate change and urban heat island mitigation techniques - the state of the art. Journal of Civil Engineering and Management. 2015, 22, 1-16. https://doi.org/10.3846/13923730.2015.1111934

2. Bhargava, A; Lakmini, S.; Bhargava, S.; Urban Heat Island Effect: It's Relevance in Urban Planning. J. Biodivers. Endanger. Species. 2017, 5, 187. https://doi.org/10.4172/2332-2543.1000187

3. Lazzarini, M.; Prashanth, M.; Ghedira, Hosni.; Temperature-land cover interactions: The inversion of urban heat island phenomenon in desert city areas. Remote Sensing of Environment. 2013, 130, 136-152. https://doi.org/10.1016/j.rse.2012.11.007

4. Mark, Z. J.; John, E.; Ten, H.; Effects of Urban Surfaces and White Roofs on Global and Regional Climate. J. Climate. 2012, 25, 1028-1044. https://doi.org/10.1175/JCLI-D-11-00032.1

5. Anna, L.P.; State of the art on the development of cool coatings for buildings and cities. Solar Energy. 2017, 144, 60-680. https://doi.org/10.1016/j.solener.2017.01.068

6. Santamouris, M.; Cooling the buildings - past, present and future. Energy and Buildings. 2016, 128, 617-638. https://doi.org/10.1016/j.enbuild.2016.07.034

7. Muscio, A.; The Solar Reflectance Index as a Tool to Forecast the Heat Released to the Urban Environment: Potentiality and Assessment Issues. Climate. 2018, 6, 12. https://doi.org/10.3390/cli6010012

8. Dornelles, K.; Caram, R.; Sichieri, E.; Natural Weathering of Cool Coatings and its Effect on Solar Reflectance of Roof Surfaces. Energy Procedia. 2015, 78, 1587- 1592. http://doi.org/10.1016/j.egypro.2015.11.216

9. Berdahl, P.; Akbari, H.; Levinson, R.; Miller, W. A.; Weathering of roofing materials - An overview. Constr. Build. Mater. 2006, 22, 423-433. http://doi.org/10.1016/j.conbuildmat.2006.10.015

10. Xue, X.; Yang, J.; Zhang, W.; Jiang, L.; Qu, J.; Xu, L.; Zhang, Z.; The study of an energy efficient cool white roof coating based on styrene acrylate copolymer and cement for waterproofing purpose-Part I: Optical properties, estimated cooling effect and relevant properties after dirt and accelerated exposures. Constr. Build. Mater. 2015, 98, 176-184. http://doi.org/10.1016/j.conbuildmat.2015.08.045

11. Synnefa, A.; Santamouris, M.; Livada, I.; A study of the thermal performance of reflective coatings for the urban environment. Solar Energy. 2006, 80, 968-981. https://doi.org/10.1016/j.solener.2005.08.005

12. Cheng, M. D; Miller, W.; New, J.; Berdahl, P.; Understanding the long-term ef- fects of environmental exposure on roof reflectance in California, Constr. Build. Mater. 2016. 26, 516-526, https://doi.org/10.1016/j.conbuildmat.2011.06.052

13. Masayuki, I.; Takashi, I.; Yoshihito, S.; Long-term performance of high-reflectivity exterior panels, Build. and Env. 2009, 44, 16011608. https://doi.org/10.1016/j.buildenv.2008.10.003

14. Bretz, S.E.; Akbar, H.; Durability of High-Albedo Roof Coatings. California Institute for Energy Efficiency, University of California. 1994. Available online: https://www.aceee.org/files/proceedings/1994/data/papers/SS94_Panel9_Paper08.pdf (accessed on 20 May 2021).

15. Revel, G. M.; Martarelli, M.; Bengochea, M. Á.; Gozalbo, A.; Orts, M. J.; Gaki, A.; Emiliani, M.; Nanobased coatings with improved NIR reflecting properties for building envelope materials: Development and natural aging effect measurement. Cement and Concrete Composites, 2013, 36, 128-135. http://doi.org/10.1016/j.cemconcomp.2012.10.002

16. Shirakawa, M.A.; de Lima, L.N.; Gaylarde, C.C.; Silva Junior, J.A.; Loz, P.H.F.; John, V.M.; Effects of natural aging on the properties of a cool surface exposed in different Brazilian environments. Energy and Buildings, 2020, 221, 110031. https://doi.org/10.1016/j.enbuild.2020.110031

17. Mastrapostoli, E.; Santamouris, M.; Kolokotsa, D.; Vassilis, P.; Venieri, D.; Gompakis, K.; On the ageing of cool roofs: Measure of the optical degradation, chemical and biological analysis and assessment of the energy impact. Energy and Buildings, 2016, 114, 191-199. http://doi.org/10.1016/j.enbuild.2015.05.030

18. Preston, H. A Case Study on the Impact of Solar Reflectance Attenuation and Roof Cleaning on a Cool Roof Return on Investment, Master's Thesis, Arizona State University, USA, December 2016.

19. Haverstic, T.; Sullivan, K.; Smithwick, J.; Impact of solar reflectance attenuation and roof cleaning on a cool roof: assessing return on investment for facility management, J. Facility Manage. Educ. Res. 2017, 1, 72-85. https://doi.org/10.22361/jfmer/81613 
20. ANSI/CRRC S100 - “Standard Test Methods for Determining Radiative Properties of Materials: Available online: https://coolroofs.org/product-rating/ansi-crrc-s100

21. American Society for Testing and Materials, G7/G7M -13, Standard practice for atmospheric environmental exposure testing of nonmetallic materials, 2013.

22. RAK Research and innovation Center: Natural Weathering Farm, https://goo.gl/maps/95xUCLjKeCRoZ8wF6

23. Jorgensen, G.; Outdoor exposure testing. In Performance and Durability Assessment: Optical Materials for Solar Thermal Systems, $1^{\text {st }}$ Eds., Kohl, M.; Carlsson, B.; Jorgensen G. J.; Czanderna, A. W.; Elsevier Science, 2004; pp. 235-253.

24. ATLAS Benchmark Exposure Sites. Available online: http://www.klimatest.eu/katalog/leaflets/atlas/Starzenie_naturalne-materialow.pdf

25. Environmental Protection Agency (EPA), Air Quality Statistics 2019. Available online: https://www.epa.gov/air-trends/air-quality-cities-and-counties

26. Federal Competitiveness and Statistics Authority, UAE. Available online: https://fcsa.gov.ae/en-us/Pages/Statistics/

27. Meteo France, Air Quality Data. Available online: https://www.meteoblue.com/en/weather/outdoorsports/airquality/sanarysur-mer france 2976258

28. American Society for Testing and Materials, C1549-15, Standard test method for determination of solar reflectance near ambient temperature using a portable solar reflectometer, 2015.

29. American Society for Testing and Materials, C1371-10, Test method for determination of emittance of materials near room temperature using portable emissometers, 2010.

30. American Society for Testing and Materials, E1980-11, Standard practice for calculating solar reflectance index of horizontal and low-sloped opaque surfaces, 2011.

31. High SRI materials: QCC Research Framework report. Personal Communication, 2013.

32. Levinson, R.; Akbari, H.; Konopacki, S.; Bretz, S.; Inclusion of cool roofs in nonresidential Title 24 prescriptive requirements. Energy Policy. 2005, 33, 151-170. http://doi.org/10.1016/S0301-4215(03)00206-4

33. Paolini, R.; Zinzi, M.; Poli, T.; Carnielo, E.; \& Mainini, A. G.; Effect of ageing on solar spectral reflectance of roofing membranes: Natural exposure in Roma and Milano and the impact on the energy needs of commercial buildings. Energy and Buildings. 2014, 84, 333-343. http://doi.org/10.1016/j.enbuild.2014.08.008

34. Ruben, U.; Pablo, V.; Jon, G.; Laura, V.; Julio, M.; Francisco, G. B.; Infrared Thermography for Temperature Measurement and Non-Destructive Testing, Sensors. 2014, 14, 12305-12348. https://doi.org/10.3390/s140712305

35. QCC-PCS-ASP030.01 Abu Dhabi Certification Scheme for High Solar Reflective Index Materials, Available on: $\underline{\text { http://jaw- }}$ dah.qcc.abudhabi.ae/en/Certifications/Product/Pages/ProductCertificationDetails.aspx

36. Peter W, The evolution of a rating system. Available online: http://rci-online.org/wp-content/uploads/2007-02-turnbull.pdf

37. Levinson, R.; Berdahl, P.; Asefawberhe, A.; Akbari, H; Effects of soiling and cleaning on the reflectance and solar heat gain of a light-colored roofing membrane. Atmospheric Environment. 2005, 39, 7807-7824. http://doi.org/10.1016/j.atmosenv.2005.08.037

38. Singh, R.P.; Tomer, N.S.; Bhadraiah, S.V.; Photo-oxidation studies on polyurethane coating: effect of additives on yellowing of polyurethane, Polym. Degrad. Stab. 2001, 73, 443-446. https://doi.org/10.1016/S0141-3910(01)00127-6 